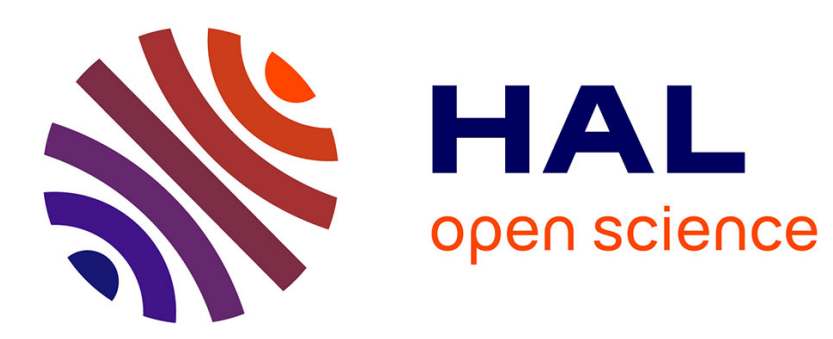

\title{
Multi-stand forest management under a climatic risk: do time and risk preferences matter?
}

Stéphane Couture, Arnaud Reynaud

\section{To cite this version:}

Stéphane Couture, Arnaud Reynaud. Multi-stand forest management under a climatic risk: do time and risk preferences matter?. 3. World congress of Environmental and Resource Economists, Jul 2006, Kyoto, Japan. 10.1007/s10666-007-9121-7 . hal-01072369

\section{HAL Id: hal-01072369 https://hal.science/hal-01072369}

Submitted on 6 Jun 2020

HAL is a multi-disciplinary open access archive for the deposit and dissemination of scientific research documents, whether they are published or not. The documents may come from teaching and research institutions in France or abroad, or from public or private research centers.
L'archive ouverte pluridisciplinaire HAL, est destinée au dépôt et à la diffusion de documents scientifiques de niveau recherche, publiés ou non, émanant des établissements d'enseignement et de recherche français ou étrangers, des laboratoires publics ou privés. 


\title{
Multi-stand Forest Management Under a Climatic Risk: Do time and Risk Preferences Matter?*
}

\author{
Stéphane Couture ${ }^{\dagger}$ and Arnaud Reynaud ${ }^{\ddagger}$
}

25th June 2007

*The authors would like to thank participants at the international conference on Economics of Sustainable Forest Management in Toronto, at the PARIS 1 seminar on Environmental and Natural Resource Economics, at the 2004 Applied Microeconomics Conference in Lille and at the $13^{\text {th }}$ annual conference of the European Association of Environmental and Resource Economists at Budapest.

${ }^{\dagger}$ LEF-INRA/ENGREF. 14, rue Girardet. CS 4216. 54042 Nancy cedex. France. E-mail: couture@nancyengref.inra.fr. fax: (33)-3-83-37-06-45, tel: (33)-3-83-39-68-60.

${ }^{\ddagger}$ LERNA-INRA, Université de Toulouse 1, Manufacture des Tabacs - Bât.F, 21 allée de Brienne, 31042 Toulouse. France. E-mail: areynaud@toulouse.inra.fr, fax: (33)-5-61-12-85-20, tel: (33)-5-61-12-85-12. 


\title{
Multi-stand Forest Management Under a Climatic Risk: Do time and Risk Preferences Matter?
}

\begin{abstract}
We propose a stochastic dynamic programming framework to model the management of a multi-stand forest under climate risk (strong wind occurrence). The preferences of the forest-owner are specified by a non-expected utility in order to separately analyze intertemporal substitution and risk aversion effects. A numerical method is developed to characterize the optimal forest management policies and the optimal consumption-saving strategy. The stochastic dynamic programming framework is applied to a non-industrial private forest-owner located in North-East of France. We show that the optimal decisions both depend upon risk and time preferences.
\end{abstract}

Keywords: Forest Economics, Stochastic Dynamic Programming, Non-expected Utility, Climate risk

JEL Codes: C61, D81, Q23 


\section{Introduction}

The economic literature on forest management has been dominated for a long time by the Faustmann-Pressler-Ohlin model, see Samuelson [1], Johansson and Löfgren [2] and Tahvonen [3] among others. This literature has traditionally focused on the management of a single stand under deterministic conditions. However, some important characteristics of forest management problems such as interdependencies between multiple tree age-classes and climatic risks call for further extensions of this classical modeling.

Several approaches have been proposed in the economic literature on forest management to address multiple tree age-class problems. For instance, Berck [4] or Johansson and Löfgren [2] have proposed a primal-dual characterization of a linear multiple age class forest model aiming at representing the timber supply. Lyon and Sedjo [5], Sedjo and Lyon [6] have developed a numerical method to solve an optimal control timber supply model based on a steady-state normal forest and, more recently, Mitra and Wan [7] or Salo and Tahvonen [8] have proposed an analytical price support method and a dynamic programming model to adress this multiple tree age-class issue. Last, Lagrangian function approaches have been considered in Salo and Tahvonen [9] and [10] and in Tahvonen [3]. One of the main question studied by these works is the convergence of the optimal forest age-class structure towards the normal forest distribution where the land area is evenly allocated over the existing ageclasses, see Tahvonen [3]. The main result of these studies is that, depending upon the characteristics of the model (discount factor level, utility form, initial age-class allocation, possibility of alternative land use,...), the optimal long-run forest structure may either converge towards a normal forest age-class structure or toward an equilibrium with unevenly allocated tree age-class structures. Recent extensions of this approach have dealt with the 
optimal allocation of land between forest and alternative uses, see Tahvonen [3] or with multiple-use forest management, see Uusivuori and Kuuluvainen [11]. Another extension has been to integrate the consumption-saving tradeoff that must be solved by the forest-owner into the context of forest management, see Tahvonen [12], Tahvonen and Salo [13], Salo and Tahvonen [10], Tahvonen [3], Uusivuori and Kuuluvainen [11]. However, all these articles consider a purely deterministic context although, for small non-industrial private forestowners, the timber production should be viewed as a risky asset that must be managed to secure consumption over the long-run. Hence, the consumption-saving tradeoff should have an impact on the forest management, and vice-versa.

Production risk is known to be an important ingredient in forest management modeling (see the seminal work by Reed [14] on forest fires or the more recent article, Haight et al. [15], for wind storms). Most of studies dealing with forest management under production risk conclude that an increase in the risk tends to reduce both the rotation length and the land expectation value. Some models have incorporated the forest-owner's risk aversion into stochastic control problems within an expected utility framework. This is the case in Caulfied [16] who uses a dominance stochastic analysis, in Taylor and Forston [17], Valsta [18], Gong and Löfgren [19] who adopt a mean-variance approach or in Kangas [20], Pukkala and Kangas [21] who use an heuristic method. The main conclusion of these works is that the impact of risk aversion on the optimal rotation is ambiguous and depends on economic and biological parameters, as well as on how risk is modeled. Caulfied [16], and Taylor and Forston [17] conclude that risk aversion tends to shorten the optimal rotation whereas Valsta [18] shows that risk aversion leads to longer optimal rotation. Gong and Löfgren [19] show that the impact of risk aversion on optimal rotation depends both on the regeneration cost and on the interest rate. One drawback of the expected utility setting used in these articles 
is that the effect of the forest-owner time and risk preferences on decision making cannot be identified, see Epstein and Zin [22] or Knapp and Olson [23]. This is especially problematic due to the long-term horizon of forest managers. Only two studies, Koskela and Ollikainen [24] and Peltola and Knapp [25], have used a non-expected utility for characterizing forestowner preferences. They both conclude that time preferences have an impact on optimal forest policies. These two articles however only consider the single age-class model.

Our study contributes to analyzing forest management in a multiple age-class setting under climatic risk. We extend the original multiple age-class model by developing a unified framework to analyze the linkage between consumption-saving, harvesting and planting decisions and risk management for a non-industrial private forest-owner facing a climatic risk. More precisely, we propose three extensions to the economic literature on optimal forest use in a stochastic environment. First, by using a non-expected utility function, we assess the impact of time and risk preferences on the optimal behavior of the forest-owner. Second, we analyze a multiple age-class forest model under climatic risk and we propose a numerical method easily implementable for solving such a class of stochastic dynamic problems. Last, we introduce saving as a decision of the forest-owner at anytime. The forest economics literature has recognized the importance of each of these features without providing a framework incorporating all of them.

The remaining of the paper is organized as follows. In Section 2, we describe the forest management model and we present the stochastic dynamic programming (SDP) method we will used. Section 3 deals with the numerical approach for solving the model calibrated for a non-industrial private forest owner located in North-East of France. In Section 4, we assess the impact of time and risk preferences. We conclude by a brief summary of our findings. 


\section{A SDP framework for multi-stand forest management}

\section{$2.1 \quad$ Specification of the model}

We consider a non-industrial private forest-owner who possesses a land area $\bar{A}$ to be allocated between forest activities and fallow. Following Tahvonen [3] or Uusivuori and Kuuluvainen [11], we assume a finite number, $I$, of tree age-classes. We denote by $A_{i, t}$ the land area (in ha) allocated to age-class $i, i=1, \ldots, I$ and by $A_{f, t}$ the fallow land at period $t, t=1, \ldots, \infty$. Trees in age-class $i$ are characterized by their timber content, $V_{i}$, measured in $\left(m^{3} / h a\right)$ and which increases with the age-class, $V_{i}>V_{i-1} \quad \forall i \geq 2$.

At each date $t$, the forest-owner plants trees on an area $a_{p, t}$, chooses the area to be harvested for the age-class $i, a_{i, t}^{h}$, and the area, $a_{f, t}$, which is voluntary converted during period $t$ from forest to fallow land $\left(a_{f, t}>0\right)$ or from fallow land to forest $\left(a_{f, t} \leq 0\right)$. At each period, by definition we have:

$$
a_{f, t}+a_{p, t}=\sum_{i=1}^{I} a_{i, t}^{h}
$$

The stochastic environment of the forest-owner is described by a risk of age-class destruction due to windstorms. The probability of tree destruction varies across age-classes, as mentioned by Dhote [26]. The stochastic event representing age-class $i$ destruction at period $t$ is denoted by $\widetilde{\epsilon}_{i, t}$ with $\widetilde{\epsilon}_{i, t}=1$ in case of age-class destruction and $\widetilde{\epsilon}_{i, t}=0$ otherwise. Trees planted at the beginning of $t$ may be affected by the stochastic event which is represented by $\widetilde{\epsilon}_{p, t}$. Once forest-decisions are taken (planting and harvesting), the risk is realized. If the stochastic event does not affect age-class $i$ then tree growth occurs. Otherwise, the fallow land is increased by the corresponding age-class $i$ area. Table 1 summarizes the dynamics of the system. One implicit assumption of having considered a finite number of age-classes is that trees beyond age-class $I$ are all identical. This explains that the dynamic equation for 
age-class $I$ area differs from the other age-class dynamics in Table 1: in case of no occurrence of the stochastic event, the area allocated to age class $I$ at the beginning of period $t+1$ is equal to the non-harvested area allocated to age-classes $I-1$ and $I$ at the beginning of $t$.

Table 1, about here

Empirical evidences (Schelhaas et al. [27]) suggest that in the case of strong windstorm, the entire production is not definitively lost. Hence, we assume that in case of an age-class destruction, a proportion $\mu \in[0,1]$ of the timber content can be recovered and sold by the forest-owner. $\mu$ equal to 1 means that strong winds do not result in timber losses and the only impact of the stochastic event is to impose harvesting at a time which may not be optimal. On contrary, $\mu$ equal to 0 means that a stand destroyed is definitively lost. The gross revenue generated by forest activities between $t$ and $t+1$ is:

$$
\sum_{i=1}^{I} P_{i} \cdot V_{i} \cdot a_{i, t}^{h}+\mu \cdot \sum_{i=1}^{I} P_{i} \cdot V_{i} \cdot\left(A_{i, t}-a_{i, t}^{h}\right) \cdot \widetilde{\epsilon}_{i, t}
$$

where $P_{i}$ represents the timber price (in euros $/ m^{3}$ ) for age-class $i$. The first term represents the revenue generated by age-classes harvesting. The revenue from the recovered tree plots, in case of strong wind occurrence, corresponds to the second term. From equation (2), another interpretation of $\mu$ could be that, in case of strong wind occurrence, all the timber volume can be recovered but only sold at a lower price $\mu \cdot P_{i}<P_{i}$ since, for instance, quality is known to be altered.

Forest activities involve three types of cost: a planting cost denoted by the function $P C($.$) ,$ an harvesting cost denoted by $H C($.$) and a recovering cost in case of the stochastic event$ occurrence denoted by $R C($.$) . Assuming that the planting cost depends upon the planted$ area and that the harvesting and the recovering costs depend upon the timber content, the 
total forest cost for period $t$ writes:

$$
P C\left(a_{p, t}\right)+\sum_{i=1}^{I} H C\left(V_{i} \cdot a_{i, t}^{h}\right)+\sum_{i=1}^{I} R C\left(V_{i} \cdot\left(A_{i, t}-a_{i, t}^{h}\right)\right) \cdot \widetilde{\epsilon}_{i, t} .
$$

Finally, the net profit generated by the forest activities, denoted by $\widetilde{\Pi}_{t}$, is equal to the revenue from forest activities given by equation (2) less the forest management costs given by equation (3). The net profit of the forest activities can be used either for consumption or for saving into a risk-free asset characterized by a given interest rate $r$. By denoting $W_{t}$ the forest-owner's wealth at date $t$, the wealth dynamic is:

$$
W_{t+1}=W_{t}(1+r)+\widetilde{\Pi_{t}}-c_{t}
$$

where $c_{t}$ is the consumption of the forest-owner, at date $t$. We assume that the consumption decision is taken once uncertainty about the stochastic event realization is resolved.

\subsection{The stochastic dynamic optimization problem}

At each period, the forest-owner determines the area of each tree age-class to be harvested, chooses the share of fallow land to be planted and decides if the revenue flow is used for consumption or for saving in order to maximize its objective function:

$$
\mathcal{P}_{1}: \begin{cases}\max _{\left\{c_{t}, a_{p, t}, a_{., t}^{h}, a_{f, t}\right\}_{t=1, \ldots, \infty}} & \mathcal{U}\left(\left\{c_{t}\right\}_{t=1, \ldots, \infty}\right) \\ \text { s.t. } & W_{t+1}=W_{t}(1+r)+\widetilde{\Pi_{t}}-c_{t} \\ & A_{1, t+1}=a_{p, t} \cdot\left(1-\widetilde{\epsilon}_{p, t}\right) \\ & A_{i, t+1}=\left(A_{i-1, t}-a_{i-1, t}^{h}\right) \cdot\left(1-\widetilde{\epsilon}_{i-1, t}\right) \forall i \in\{2, \ldots, I-1\} \\ & A_{I, t+1}=\left(A_{I-1, t}-a_{I-1, t}^{h}\right) \cdot\left(1-\widetilde{\epsilon}_{I-1, t}\right)+\left(A_{I, t}-a_{I, t}^{h}\right) \cdot\left(1-\widetilde{\epsilon}_{I, t}\right) \\ & A_{f, t+1}=A_{f, t}+a_{f, t}+a_{p, t} \cdot \widetilde{\epsilon}_{p, t}+\sum_{i=1}^{I}\left(A_{i, t}-a_{i, t}^{h}\right) \cdot \widetilde{\epsilon}_{i, t} \\ & \sum_{i=1}^{I} A_{i, t}+A_{f, t}=\bar{A} \\ & \left(A_{., 0}, A_{f, 0}, W_{0}\right) \text { given }\end{cases}
$$


where $\mathcal{U}($.$) represents the objective function of the forest-owner, a_{., t}^{h}=\left(a_{1, t}^{h}, \ldots, a_{I, t}^{h}\right)$ is the vector of harvested areas and $A_{., t}=\left(A_{1, t}, \ldots, A_{I, t}\right)$ is the vector of areas allocated to each tree age-class.

Since the problem is dynamic and stochastic, the optimal decision path should both depend on forest-owner risk and time preferences. Risk preferences refer to the forest-owner desire to smooth consumption across states of the nature whereas time preferences reflect the forest-owner propensity to limit consumption fluctuations over time. Historically, the expected utility model (EU) has been the most common way to integrate risk preferences into forest planning, and more generally into natural resource management problems. However, in the case of dynamic and stochastic environments, using the EU model raises a number of substantial issues. First, as stressed by Epstein and Zin [22], this framework does not allow to make a distinction between preferences toward risk and time since both concepts are encompassed into the curvature of the utility function. This is especially problematic in the case of forest management since there is a priori no reason to believe that these preferences should be linked. A second drawback of the EU framework is that the decision-maker only takes into account the final consequences of his choices, neglecting the timing of uncertainty resolution: the individual's choice behavior is independent of the dynamic choice problem he is facing. Given the very long time horizon of the forest-owner, such a property of the EU model is clearly problematic. Last, as recently stressed by Chavas [28], concerns about the future likely vary with income level. It follows that discounting the future should both depend upon income and consumption levels. This suggests a move away from the standard time additive models, where utility of future consumption is discounted at a constant rate.

Recursive preferences have been proposed as a way to incorporate time and risk preferences into the decision-maker problem. Moreover, in a model with recursive preferences, 
the decision-maker integrates the timing of uncertainty resolution as a part of the decision problem. Following Epstein and Zin [22, 29], we use an isoelastic formulation of Kreps and Porteus preferences. Hence, the forest-owner's objective function is given by its recursive utility at time $t, U_{t}$ defined by:

$$
U_{t}=\left\{(1-\beta) \cdot c_{t}^{\frac{\sigma-1}{\sigma}}+\beta\left[\mathrm{E} U_{t+1}^{1-\alpha}\right]^{\frac{(\sigma-1) / \sigma}{1-\alpha}}\right\}^{\frac{\sigma}{\sigma-1}}
$$

where $\beta \in[0,1]$ is the subjective discount factor, $\alpha \in] 0, \infty)$ is the Arrow-Pratt constant relative risk-aversion, $\sigma \in] 0, \infty)$ is elasticity of intertemporal substitution (EIS) and $\mathrm{E}$ is the expectation with respect to all stochastic variables of the model. The left handside term in parentheses of equation (6) gives the utility directly derived from consumption at date $t$. The right handside term measures the expected future utility given the information available at date $t$. Aggregation of both terms then depends upon risk and time preferences of the decision-maker. Notice that the recursive preferences nest the EU model as a special case since by setting $\sigma=\frac{1}{\alpha}$, we get the familiar constant relative risk aversion expected utility function.

\subsection{Solving the stochastic dynamic programming problem}

The stochastic control problem consists in choosing a sequence of decision rules that maximizes the objective function (6) subject to the previously defined equations of motion and constraints in $\mathcal{P}_{1}$. Since the problem is autonomous, we can drop the time subscript and make the value function of the problem solely dependent on the initial conditions for any period (all model parameters and functions are the same for all decision stages, which means that the problem is stationary). The stochastic dynamic recursive equation defining the 
optimal forest and saving management is:

$J\left(A_{.}, A_{f}, W\right)=\operatorname{Max}_{\left\{c, a_{p}, a_{,}^{h}, a_{f}\right\}}\left\{(1-\beta) \cdot \mathrm{E} c^{\frac{\sigma-1}{\sigma}}+\beta\left[\mathrm{E} J^{1-\alpha}\left(A_{,}, A_{f}, W\right)\right]^{\frac{\sigma-1}{\sigma-\alpha}}\right\}^{\frac{\sigma}{\sigma-1}}$

where $J($.$) is the value function. We have to solve a stochastic dynamic programming prob-$ lem. Since the discount factor is bounded, the mapping underlying the Bellman's equation is a strong contraction on the space of bounded continuous functions and, thus it yields to a unique value function. A value iteration method will be used for solving the SDP problem, see Judd [30]. As it will be discussed in the next section, it consists in assigning an initial guess for the value function, and then in recursively solving the maximization problem until the implied carry-over value function converges to an invariant approximation.

\section{Solving the SDP model}

\subsection{Calibration of the SDP model}

The model has been calibrated to represent the behavior of a non-industrial private forestowner located in Lorraine, a region located in North-East of France. The private forest estate is assumed to produce spruce, one of the most common stands observed in Lorraine. With 25 million cubic meters on the ground, Lorraine was the second devastated French region by the December 1999 exceptional storms.

Following Salo and Tahvonen ([8]) and Uusivuori and Kuuluvainen [11] who have respectively considered 6 and 4 age-class models, we consider 5 tree age-classes, $I=5$. Given the growth process of spruce, the time index $t$ represents a 20 year interval. Hence, the age-class $i$ corresponds to trees of age $20 * i$ at the beginning of period $t$. The volume per ha and the price for each age-class for spruce in North-East of France are presented in Table 2. 
Table 2, about here

The cost functions associated to forest management (planting, harvesting and recovering cost) are assumed to be linear and are derived from Guo [31]. The unit cost of planting, harvesting and recovering tree plots are respectively 2.1038 thousand euros per ha, 0.0037 and 0.0055 thousand euros per cubic meter. Last, in case of the stochastic event occurrence, $10 \%$ of the forest area can be recovered and sold ( $\mu$ is equal to 0.1 ).

The stochastic event represents the risk of tree plot loss due to strong winds. According to Picard et al. [32], the annual probability of strong wind realization is $3.1^{0} / 00$ for France. Assuming that strong wind occurrences are i.i.d, the probability of observing at least one strong wind during a twenty-year period, denoted by $p$, is computed from the binomial distribution $X \backsim \operatorname{Bin}(20,0.0031)$ and is equal to $6.02 \%$. Notice that, in the economic literature on forestry, catastrophic events have often been modeled using a Poisson process (Reed [14], Haight et al. [15]). We do not strictly depart from this literature since the binomial law converges in distribution toward a Poisson process (for a sufficient number of trials and a low probability). Given a strong wind occurrence, trees may or may not be destroyed. We denote by $q_{i}$ the conditional probability of overturning for age-class $i$ given strong wind occurrence. As suggested by Dhote [26], this conditional probability increases with the age-class varying from $1 \%$ for the first age-class to $72 \%$ for the fifth, see Table 2 . Applying the Bayes formula, the unconditional probability of age-class $i$ destruction is $p \cdot q_{i}$, see the last column in Table 2. Given the stochastic specification of the model, there are, at each period, 33 possible states of the nature. In the first state of the nature, the strong wind does not occur and the associated probability is $1-p=0.94$. The $32=2^{5}$ remaining states of the nature correspond to the realization of the strong wind with or without production 
loss for each age-class. The associated probabilities are used to derive the expectation in the Bellman's equation (7).

We have normalized the area of the land to 1 ha, $\bar{A}=1$. This reflects the French situation since approximately $68 \%$ of non-industrial private forest-owners hold less than one hectare. This assumption is not restrictive and higher forest areas may be considered. Forest-owners are also characterized by their time and risk preferences but here is currently no estimation available for these parameters in the case of small forest-owners. More generally, there is no consensus on the level of the EIS and on the coefficient of risk aversion for economic agents. For instance, according to the study considered, the consumer EIS may range from zero, Hall [33], all the way to 0.87, Epstein and Zin [29]. For the risk aversion coefficient, $\alpha$ ranges from 0.82, Epstein and Zin [29] to 1.5, Normandin and Saint-Amour [34]. By reference to Epstein and Zin [22] and previous empirical studies, we have considered the following values $\beta=0.98, \alpha=0.9$ and $\sigma=1 / 2$. These values are consistent with the range of reported estimates in the economic literature. They correspond to a low level of risk aversion and a high willingness to substitute consumption across time. This case will be termed the recursive utility benchmark case in the remaining of the article.

\subsection{Solving the SDP problem}

We need to estimate the value function $J\left(A, A_{f}, W\right)$ defined by the recursive equation $(7)$. Given the high non-linearity of the problem, no analytical solution of this equation can be found. Hence a numerical procedure must be implemented. We use a value iteration approach that is we seek a numerical approximation $\widehat{J}($.$) to the infinite horizon value function that$ maximizes the value of the problem resulting from decisions carried out in the future. The main steps of the value iteration algorithm are presented in Judd [30], chapter 12. We propose 
here to extend the approach followed by Howitt et al. [35] to the case of multi-dimensional state variables. In order to solve the Bellman's equation, a specific functional form for $\widehat{J}($. must be chosen to approximate the solution to the infinite-horizon problem. Howitt et al. [35] have for instance used a Chebychev Polynomial form. The main difficulty with this class of polynomial approximation is that the number of parameters to be estimated exponentially increases with the number of state variables. Since 7 state variables must be considered in our SDP problem, we have used a more simple second-order polynomial approximation. However, since neither the objective function is quadratic nor the constraints are linear, the value function is not quadratic. An important issue we will discuss in the next paragraph is to ex-post check that the second-order polynomial approximation is an accurate approximation of the unknown value function. The polynomial approximation simply writes:

$$
\begin{aligned}
\widehat{J}\left(A, A_{f}, W\right)= & \sum_{i} \eta_{i} \cdot A_{i}+\eta_{F} \cdot A_{f}+\eta_{W} \cdot W \\
& +\sum_{i} \eta_{i i} \cdot A_{i} A_{i}+\eta_{f f} \cdot A_{f} A_{f}+\eta_{W W} \cdot W W \\
& +\sum_{i} \eta_{W i} \cdot W A_{i}+\eta_{W f} \cdot W A_{f} \\
& +\sum_{i} \eta_{f i} \cdot A_{f} A_{i} \\
& +\sum_{i, j / j>i} \eta_{i j} \cdot A_{i} A_{j} .
\end{aligned}
$$

The polynomial approximation is characterized by 35 parameters that must be estimated. In order to make the SDP numerically operational, the state variables must be discretized. The wealth's stock has been discretized in 3 points $\{10,40,70\}$ and areas allocated to each age-class or to fallow into 6 points uniformly distributed between 0 and 1 . Since the total area has been normalized to 1 ha, the state variables can be interpreted as proportions.

The value function iteration program has been written in GAMS. The code and the data are available from authors for replication of results. 


\subsection{The solution to the empirical SDP problem}

\subsubsection{Accuracy of the second-order polynomial approximation}

The stabilization of value function parameters has been achieved after 260 iterations and a few hours of computing time. At the $260^{\text {th }}$ iteration, the sum of squared errors between parameter estimates is smaller than 0.00001 . This means that the value iteration algorithm converges toward a stable approximation of the value function within the class of second-order polynomial forms. In order to evaluate the accuracy of the second-order approximation, the SDP has also been solved with a third-order polynomial form and we have compared the resulting estimated value functions at each grid point. The two polynomial approximations give similar results especially for interior grid points, the average and the maximum absolute relative difference being respectively $2.15 \%$ and $6.25 \%$. We believe that the second-order polynomial form offers a valid approximation for two main reasons. First, high absolute relative differences between the two approximations are observed for exterior grid points, the $6.25 \%$ difference corresponding for instance to an unlikely situation where all the area is used by the forest-owner as fallow. Second, it is not to possible to determine if those differences should be attributed to the higher flexibility of the third-order form or, on contrary, to a lack of convergence of third-order coefficients. Moreover, the computing time is more than 10 times higher with the third-order polynomial approximation (189 parameters must be estimated compared to 35 with the second-order approximation), the computing time for one iteration being 6 minutes on a computer with a pentium $1600 \mathrm{Mhz}$ processor. In term of cost-benefit analysis, the precision loss due to the second-order polynomial approximation seems largely balanced by the increased speed of the value iteration algorithm. A last accuracy check of the second-order polynomial approximation has been to compute the 
residuals of the Bellman's equation (7) at each discretized point. The residuals are small enough for considering that the second-order polynomial form is a good approximation of the unknown value function. Although the true value function is not quadratic, the second-order polynomial approximation offers an accurate approximation.

\subsubsection{The estimated value function}

Table 3 gives the 35 coefficients of the value function of the SDP problem. The estimated value function possesses good concavity properties as it increases with each state variable, but at a decreasing rate.

Table 3, about here

The coefficients $\eta_{W i}$ reflecting the link between the wealth and the tree age-class areas worth being investigated. The sign associated with coefficients $\eta_{W i}$ results from three effects. First, in case of a low level of wealth, the marginal value of harvesting age-class plots is high as consumption is constrained. This has a negative impact on the value of age-class plots. As harvesting is highly valued by customers, it is optimal to harvest important quantity of wood which can be achieved only if the value of age-class plots is low. This wealth effect results in negative parameters $\eta_{W i}$. Second, in case of a low level of wealth, the forest-owner may prefer reducing risk exposition. This implies a low value associated with tree age-class plots. This risk exposition effect results in negative parameters $\eta_{W i}$. On the contrary, in case of a low level of wealth, harvesting age-class plots implies low age-class areas at the beginning of the next period and a high risk of lowering future consumption. In order to reduce the cost of a low future consumption, tree age-class plots must be attributed a high value. This continuation effect results in positive parameters $\eta_{W i}$. The optimal value of age-class plots 
and the optimal harvesting and planting strategies balance these three effects. For ageclasses 1 to 4, the continuation effect dominates the two other effects (at a decreasing rate with tree age). For the fifth age-class, the wealth and the risk exposition effects dominate. Keeping oldest trees is risky and harvesting is more likely to be the optimal strategy.

Figure 1, about here

Next, we investigate how the age-class plot value differs among age-classes. In Figure 1, we have plotted the value of a given age-class (assuming that no other age-class is planted at the same time) as a function of forest-owner wealth. For instance, the curve corresponding to $A_{1}$ gives the value of one hectare planted with the first age-class. This value measures the expected flow of utility that will result from an optimal forest use in the future. Since fallow must be planted before being able to generate any positive profit, the value to be attributed to fallow is lower than the value of any tree age-class. Second, for a given level of wealth, the value of an age-class area increases with the age-class. This is an intuitive result since the older is a tree age-class, the higher is the profit per unit of area. Third, the difference between tree age-class value functions appears to be finally quite limited. For example, the value of the age-class 3 area is less than $5 \%$ higher than the value associated with the age-class 2 area. This is surprising compared to the value per ha, more than three times higher for age-class 3 . One possible explanation is that the revenue from saving dominates the revenue from age-class plots. Last, the difference between age-class area values decreases with the wealth stock. This is also intuitive. In the case of a low level of wealth, maintaining the consumption flow requires to harvest age-class plots. Hence, the continuation effect is limited and the value of an age-class plot is more driven by its instantaneous return. In the case of a high wealth level, the consumption flow more largely depends on saving. The 
impact of the climatic risk on the value of age-class plots is limited because consumption is secured by the high wealth stock and the continuation effect dominates, in such a case, the two other effects.

\section{Assessing the impact of time and risk preferences}

In this section, we investigate how risk and time preferences impact on the optimal forestowner decisions, on the long-run equilibrium of the model and on the dynamic paths.

\subsection{Time, risk preferences and optimal policies}

We consider an initial land allocation where each tree age-class is attributed the same area (20\% of the total area) and we characterize the optimal forest and non-forest decisions.

Table 4, about here

We first focus on the optimal forest strategies in the recursive utility benchmark case, see Table 4 . In the case of a low wealth level $(W=10$ or $W=20)$, age-classes 3 to 5 are harvested. The wealth and the risk exposure effects dominate the continuation effect and it is optimal to harvest the young tree age-classes. As the wealth level increases, consumption is less constrained, even in the case of strong winds, and the forest-owner is ready to take more risks, that is to expose older age-classes to the climatic risk (in order to get higher returns). For a very high level of wealth $(W=60)$, neither harvesting nor planting are optimal strategies. The consumption flow only relies on saving. This explains why, in Figure 1, the value of the age-class plots converges toward a unique equilibrium as the wealth level increases. In an EU context with a higher EIS $\left(\sigma=\frac{1}{\alpha}=1.11>0.9\right)$, it is optimal to 
harvest age-classes 4 and 5 for an initial wealth equal to 20. Compared to the recursive utility benchmark case, the forest-owner doesn't harvest age-class 3 which corresponds to transferring a current consumption toward a future one. This is made possible by the higher EIS which means that substitution across periods is more desirable and that consumption can fluctuate over time. A symmetric result is obtained for an initial wealth level equal to 50. In that case, it is optimal to harvest age-classes 4 and 5 in an expected utility context with a higher EIS whereas, in the recursive utility benchmark case, harvesting is restricted to the fifth age-class. A higher EIS allows to transfer a future consumption toward current one if the wealth level is high enough.

Next we investigate, for different wealth levels, the consumption-saving tradeoff still assuming that each tree age-class is attributed $20 \%$ of the total area. The optimal consumptionsaving decisions are reported in Table 5. As the initial wealth increases, the consumption flow more heavily depends on saving. For the highest initial wealth level, $W=60$, consumption is made possible exclusively using saving since no tree age-class is harvested. As it could be expected, the flow of consumption increases with the initial wealth. Moreover, the higher is the initial wealth, the higher is the share of consumption to the available wealth (from less than $30 \%$ if $W=10$ to around $50 \%$ in the higher initial wealth case, $W=60$ ).

\subsection{Time, risk preferences and the long-run equilibrium}

In this subsection, we simulate the model over a very long time horizon (400 periods) for various levels of the EIS $(\sigma)$ and the Arrow-Pratt constant relative risk-aversion coefficient $(\alpha)$, assuming that no catastrophic event occurs. Such a situation allows us to analyze the long-run equilibrium of the dynamic model, as presented in Table 6. 
Table 6, about here

For each $(\alpha, \sigma)$, all state variables converge toward a unique long-run equilibrium for which only the fifth tree age-class is harvested. This result could be related to the high level of wealth at the equilibrium, higher than 50. At this wealth level, the continuation effect dominates the risk exposure and the wealth effects. Second, at the long-run equilibrium the areas dedicated to age-classes 1 to 4 are the same: $A_{1}^{L R}=\cdots=A_{4}^{L R}$. This result comes directly from the fact that these age-classes are not harvested. Notice finally that, at the long-run equilibrium, the area allocated to age-classes 1 to 4 differs from the fifth age-class plot, $A_{5}^{L R}$. This may result from the fact that, as the growth process is finite, the dynamic of the last age-class differs from other age-class dynamics. Without strong wind occurrence, the optimal forest management tends toward a normal forest structure where only the oldest tree age-class is harvested. Notice that the convergence of optimal forestry programs toward a normal forest structure has recently received a considerable attention in the forest economics literature (see Salo and Tahvonen [10], and Uusivuori and Kuuluvainen [11] among others).

We wish now to investigate the impact of the forest-owner time preferences on the longrun equilibrium. For a given level of the risk parameter, the lower is the EIS, the higher is the saving and the lower is the age-class 5 area. The explanation is quite intuitive. Lowering the EIS implies that substitution across periods is less desirable. Hence, consumption should be stabilized over time. This can be achieved first though a high level of saving (with a risk-free return $r$ ) and second, through a lower final forest area exposed to the catastrophic risk. This second mechanism is made possible by harvesting a higher proportion of tree plots. In other words, a higher saving and a higher harvesting rate provide a greater insurance against the variation of consumption due to catastrophic events. 
The nature of the impact of the risk preferences on the long-run equilibrium is less straightforward. In case of a high level of EIS $(\sigma=2 / 3)$, the higher is the parameter of risk aversion, the higher is the saving and the lower is the age-class 5 forest area. This can be explained intuitively. A risk averse forest-owner wants to secure income. This can be achieved by having a higher level of wealth and a lower area dedicated to the fifth age-class. In case of a low level of EIS $(\sigma=1 / 3)$, the relationship between risk aversion and wealth (or tree plots) appears to be non monotonic.

The preferences for intertemporal substitution seem to have a much more important effect on the system than risk preferences. This is a striking result in view of the importance of risk aversion in static models of risk and uncertainty. We do not have a full explanation of this result but we conjecture that it may result from the difference in the structure of decision making between the static and dynamic cases. In the static case, decisions are made before uncertainty is resolved thus the net returns bear the full brunt of uncertainty. In the dynamic case, some decisions are taken after uncertainty is resolved (this is the case here for the consumption choice). It may be possible that some of the adverse effects of uncertainty in the static case are mitigated in the dynamic case, even before risk aversion is considered. Another explanation is that, at the long-run equilibrium without risk occurrence, the value of tree plots may become too low compared to saving. In such a case, the catastrophic risk will only have a minor impact on forest-owner wealth and risk does not matter as much as intertemporal substitution. Notice that in an one-period age-class model, Peltola and Knapp [25] have also found that the intertemporal elasticity of substitution does significantly affect forest management. In particular, they have shown that with a low EIS, harvesting starts sooner as the forest-owner does not want to postpone consumption for the sake of a higher biological productivity. With a high EIS, consumption is on contrary sacrificed at the 
beginning for a gain in future biological productivity.

\subsection{Time, risk preferences and optimal dynamic paths}

Finally, we analyze the optimal management of tree age-classes and wealth stock in a situation where the catastrophic risk may occur. Compared to the previous paragraph the model has still been simulated over 400 periods but, at each date, the realization of the stochastic event is drawn from the binomial distribution $\operatorname{Bin}(20,0.0031)$.

Figure 2, about here

Figure 2 presents how the dynamics of wealth and consumption react to the occurrence of strong wind events in the recursive utility benchmark case for the 50 first periods. As it can be seen, a strong wind event is realized at date 25 . The instantaneous impact of the strong wind event is to increase the forest-owner wealth stock (as $10 \%$ of the tree age-classes destroyed can be recovered and sold) from the long-run equilibrium, 55.01 to a higher level, 65.75. The realization of strong wind may appear to be "good news" for the forest-owner as the wealth's stock initially increases but the strong wind realization implies a loss of surplus because first, it imposes a harvest at a date that may not be optimal and second, it generates higher future costs. At the same time some tree age-classes are lost (age-classes 4 and 5) and the proportion of fallow increases. The forest-owner anticipates that the future consumption will have to be reduced (due to forest planting costs and since the new tree age-class will be harvested later). Hence, the annual consumption falls from the long-run equilibrium level, 1.76, to 1.38. During the following period, all the fallow land (59\% of the total area) is replanted with a new tree age-class. As a consequence, the wealth stock decreases and at the same time the consumption increases. Finally, the dynamic of the system starts converging 
toward the long-run equilibrium.

We have conducted some sensitivity analysis by modifying the level of the constant relative risk aversion coefficient. Both the consumption and the wealth dynamic paths are not significantly affected by these changes. The time preferences of the forest-owner seem to have a much more important impact. Hence, we show that the deviations from the long-run equilibrium, both in terms of wealth and consumption, increase significantly with the EIS. This result is intuitive since, as mentioned previously, a low EIS implies that substitution across periods is less desirable and that consumption should be stabilized over time. This is made possible through a higher level of precautionary saving.

These simulations suggest that time preferences profoundly affect both forest management decisions and the optimal consumption-saving dynamic path. Hence, the decisionmaker time and risk preferences should be viewed as important features of any framework aiming at modeling forest-owner's decisions facing a climatic risk.

\section{Conclusion}

We have used a non-expected utility approach (recursive preferences) for jointly analyzing the saving and forestry decisions of a small forest-owner facing a climatic risk. This approach can contribute to forestry management as well as to natural resource economics under risk by providing an alternative structure to the usual expected utility model. Hence, the class of recursive preferences allows to separately analyze the impact of risk and time preferences on the optimal decisions of the forest-owner whereas these two distinct concepts are unattractively linked within the expected utility model. In order to solve the stochastic dynamic programming problem, we have extended the numerical approach followed by Howitt et al. 
[35] to the case of multi-dimensional state variables.

We have applied the stochastic dynamic programming model to the management of a French forest-owner facing a strong wind risk. We have first shown that the linkage between consumption-saving decisions and forest management is a complex issue. This relationship is driven by a wealth, a risk-exposure and a continuation effects. The net impact of these effects crucially depends on the forest-owner's wealth. For instance, for a low level of wealth the risk-exposure effect and the wealth effect dominate the continuation effect. Hence, it is optimal to harvest young tree age-classes. On contrary, for higher wealth levels, the continuation effect dominates and only the oldest age-classes are harvested. This suggests that concerns about the future likely vary with income level. Hence, discounting the future should both depend upon income and consumption levels. A move away from the standard time additive models, where utility of future consumption is discounted at a constant rate, seems justified. We have also demonstrate that time and risk preferences affect the forest-owner's decisions (consumption, harvesting and planting) in a very different way. The numerical simulations have revealed that the impact of risk aversion on harvesting and saving decisions is not straightforward. The behavior of the forest-owner is more driven by intertemporal substitution preferences than by risk aversion. This constitutes another important motivation from moving away from the expected utility framework.

There are several possible directions for future researches. First, some form of insurance could be introduced into the model (private insurance, self-insurance or public funds). Another possible extension could be to take into account self-protection of forest-owners. In that case the conditional probability of forest loss is affected by forest-owner decisions. The problem is no more stationary and the Bellman's equation can not be solved using conventional stochastic dynamic programming techniques. Last, there is now an important 
literature on non-market value of forests. Introducing these valuations could significantly alter the optimal duration of rotations. It has been shown, for instance, that the rotation length of tree stands is an effective way for managing the forest carbon budget see, Stainback and Alavalapati [36] or Stollery [37]. The forest-owner should then balance longer rotations favorable to carbon sequestration with the risk increase.

\section{References}

[1] P. Samuelson, Economics of forestry in a evolving society, Economic Inquiry 14 (1976) 466-492.

[2] P. Johansson, K. Löfgren, The economics of forestry and natural resources, Basil Blackwell, Oxford, UK, 1985.

[3] O. Tahvonen, Optimal harvesting of forest age classes: a survey of some recent results, Mathematical Population Studies 11 (2004) 205-232.

[4] P. Berck, The economics of timber: A renewable resource in the long-run, Bell Journal of Economics 10 (1979) 447-462.

[5] K. Lyon, R. Sedjo, An optimal control theory model to estimate the regional long run timber supply, Forest Science 29 (1983) 798-812.

[6] R. Sedjo, K. Lyon, The long-term adequacy of world timber supply, report, Resources for the Future RFF. Washington DC (1990).

[7] T. Mitra, H. Wan, Some theoretical results on the economics of forestry, Review of Economic Studies 52 (1985) 263-282. 
[8] S. Salo, O. Tahvonen, On the optimality of a normal forest with multiple land classes, Forest Science 48 (2002) 530-542.

[9] S. Salo, O. Tahvonen, On the economics of forest vintages, Journal of Economic Dynamics and Control 27 (2003) 1411-1435.

[10] S. Salo, O. Tahvonen, Renewable resources with endogenous age classes and allocation of land, American Journal of Agricultural Economics 86 (2) (2004) 513-530.

[11] J. Uusivuori, J. Kuuluvainen, The harvesting decisions when a standing value forest with multiple age-classes has value, American Journal of Agricultural Economics 87 (1) (2005) 61-76.

[12] O. Tahvonen, Bequests, credit rationing and in situ values in the faustmann-presslerohlin forestry model, Scandinavian Journal of Economics 100 (4) (1998) 781-800.

[13] O. Tahvonen, S. Salo, Optimal forest rotation with in situ preferences, Journal of Environmental Economics and Management 37 (1999) 106-128.

[14] W. Reed, The effects of the risk of fire on the optimal rotation of a forest, Journal of Environmental Economics and Management 11 (1984) 180-190.

[15] R. Haight, W. Smith, T. Starka, Hurricanes and the economics of loblolly pine plantations, Forest Science 41 (4) (1995) 675-688.

[16] J. Caulfield, A stochastic efficiency approach for determining the economic rotation of a forest stand, Forest Science 34 (1988) 441-457.

[17] R. Taylor, J. Forston, Optimum plantation planting density and rotation age based on financial risk and return, Forest Science 37 (3) (1991) 886-902. 
[18] L. Valsta, A scenario approach to stochastic anticipatory optimization in stand management, Forest Science 38 (1992) 430-447.

[19] P. Gong, K.-G. Löfgren, Impact of risk aversion on optimal rotation age (2005).

[20] J. Kangas, Incorporating risk attitude into comparison of reforestation alternatives, Scandinavian Journal of Forest Research 9 (1994) 297-304.

[21] T. Pukkala, J. Kangas, A method for integrating risk and attitude toward risk into forest planning, Forest Science 42 (2) (1996) 198-205.

[22] L. Epstein, S. Zin, Substitution, risk aversion and the temporal behavior of consumption and asset returns: A theoretical framework, Econometrica 57 (1989) 937-969.

[23] K. Knapp, L. Olson, Dynamic resource management: Intertemporal substitution and risk aversion, American Journal of Agricultural Economics 78 (1995) 1004-1014.

[24] E. Koskela, M. Ollikainen, Timber supply, amenity values and biological uncertainty, Journal of Forest Economics 5 (2) (1999) 285-304.

[25] J. Peltola, K. Knapp, Recursive preferences in forest management, Forest Science 47 (4) (2001) 455-465.

[26] J. Dhote, Composition, structure et résistance des peuplements, in Les écosystèmes forestiers dans la tempête, J.C. Bergonzini and O. Laroussinie, Eds. ECOFOR-MAP, Paris, 2000.

[27] M.-J. Schelhaas, G.-J. Nabuurs, A. Schuck, Natural disturbances in the european forests in the 19th and 20th centuries, Global Change Biology 9 (2003) 1620-1633. 
[28] J.-P. Chavas, On impatience, economic growth and the environmental kuznets curve: A dynamic analysis of resource management, Environmental and Resource Economics 28 (2) (2004) 123-152.

[29] L. Epstein, S. Zin, Substitution, risk aversion and the temporal behavior of consumption and asset returns: An empirical analysis, Journal of Political Economy 99 (1991) 263286.

[30] K. Judd, Numerical Methods in Economics, M.I.T Press, Cambridge, 1998.

[31] B. Guo, Recherche d'une sylviculture optimale à long terme pour les peuplements forestiers équiennes, Phd dissertation, ENGREF, Nancy, 1994.

[32] O. Picard, N. Robert, E. Toppan, Les systèmes d'assurance en forêt et les progrès possibles, rapport IDF (2002).

[33] R. Hall, Intertemporal substitution in consumption, Journal of Political Economy 96 (1988) 338-357.

[34] M. Normandin, P. Saint-Amour, Substitution, risk aversion, taste shocks and equity premia, Journal of Applied Econometrics 13 (1998) 265-281.

[35] R. Howitt, A. Reynaud, S. Msangi, K. Knapp, Estimating intertemporal preferences for natural resource allocation, American Journal of Agricultural Economics 87 (4) (2005) 969-983.

[36] G. Stainback, J. Alavalapati, Modeling catastrophic risk in economic analysis of forest carbon sequestration, Natural Resource Modeling 17 (3) (2004) 299-317.

[37] K. Stollery, Climate change and optimal rotation in a flammable forest, Natural Resource Modeling 18 (1) (2005) 91-112. 
[38] B. Vannière, Tables de production pour les forêts françaises, E.N.G.R.E.F Press, Nancy, 1984. 
Table 1: Dynamics of the forest system

\begin{tabular}{l|cccl}
\hline & $\begin{array}{c}\text { Age-class and } \\
\text { fallow areas } \\
\text { at } t\end{array}$ & $\begin{array}{c}\text { Decisions } \\
\text { Planting }\end{array}$ & $\begin{array}{c}\text { Stochastic } \\
\text { event }\end{array}$ & $\begin{array}{c}\text { Age-class and } \\
\text { fallow areas } \\
\text { at } t+1\end{array}$ \\
age-class 1 & $A_{1, t}$ & $a_{p, t}$ & $\widetilde{\epsilon}_{p, t}$ & \\
age-class 2 & $A_{2, t}^{h}$ & $a_{2, t}^{h}$ & $\widetilde{\epsilon}_{1, t}$ & $\begin{array}{l}A_{1, t+1}=a_{p, t} \cdot\left(1-\widetilde{\epsilon}_{p, t}\right) \\
\vdots\end{array}$ \\
$\vdots$ & $\vdots$ & $\vdots$ & $\vdots$ & $\vdots$ \\
age-class $i$ & $A_{i, t}$ & $a_{i, t}^{h}$ & $\widetilde{\epsilon}_{i, t}$ & $A_{i, t+1}=\left(A_{i-1, t}-a_{i-1, t}^{h}\right) \cdot\left(1-\widetilde{\epsilon}_{i-1, t}\right)$ \\
$\vdots$ & $\vdots$ & $\vdots$ & $\vdots$ & $\vdots$ \\
age-class $I-1$ & $A_{I-1, t}$ & $a_{I-1, t}^{h}$ & $\widetilde{\epsilon}_{I-1, t}$ & $A_{I-1, t+1}=\left(A_{I-2, t}-a_{I-2, t}^{h}\right) \cdot\left(1-\widetilde{\epsilon}_{I-2, t}\right)$ \\
age-class $I$ & $A_{I, t}$ & $a_{I, t}^{h}$ & $\widetilde{\epsilon}_{I, t}$ & $A_{I, t+1}=\left(A_{I-1, t}-a_{I-1, t}^{h}\right) \cdot\left(1-\widetilde{\epsilon}_{I-1, t}\right)$ \\
Fallow & & & & $+\left(A_{I, t}-a_{I, t}^{h}\right) \cdot\left(1-\widetilde{\epsilon}_{I, t}\right)$ \\
& $A_{f, t}$ & $A_{f, t}$ & & $A_{f, t+1}=A_{f, t}+a_{f, t}+a_{p, t} \cdot \widetilde{\epsilon}_{p, t}$ \\
& & & & $+\sum_{i=1}^{I}\left(A_{i, t}-a_{i, t}^{h}\right) \cdot \widetilde{\epsilon}_{i, t}$ \\
\hline
\end{tabular}


Table 2: Characteristics of tree age-classes

\begin{tabular}{lccccc}
\hline Age-class & $\begin{array}{c}V_{i}^{a} \\
\text { Timber } \\
\text { content }\end{array}$ & $\begin{array}{c}P_{i}^{b} \\
\text { Timber } \\
\text { price }\end{array}$ & $\begin{array}{c}\text { Annual } \\
\text { return }\end{array}$ & $\begin{array}{c}q_{i} \\
\text { Conditional } \\
\text { probability of } \\
\text { overturning }\end{array}$ & $\begin{array}{c}p \cdot q_{i} \\
\text { Unconditional } \\
\text { probability of } \\
\text { age-class loss } \\
\left(\mathrm{m}^{3} / \mathrm{ha}\right)\end{array}$ \\
\hline 1 & 24.60 & 0.1303 & 12.48 & 1 & 0.06 \\
\hline 2 & 112.20 & 1.3688 & 9.50 & 30 & 1.75 \\
3 & 353.50 & 8.4133 & 4.94 & 65 & 3.79 \\
4 & 601.40 & 22.0713 & 1.71 & 71 & 4.14 \\
5 & 694.70 & 30.9836 & 0.14 & 72 & 4.20 \\
\hline${ }^{a}:$ Adapted from Vannière [38]. $V_{i}$ corresponds to the timber content for $20^{*} i$ year old trees. \\
${ }^{b}:$ From Guo [31]. $P_{i}$ corresponds to the timber price for $20^{*} i$ year old trees. \\
${ }^{c}:$ Using Picard et al. [32] and based on forest expert interviews.
\end{tabular}

Table 3: Estimated parameters of the value function in the recursive utility benchmark case

\begin{tabular}{|c|c|c|c|c|c|c|c|}
\hline & \multirow[t]{2}{*}{ Wealth } & \multicolumn{5}{|c|}{ age-classes } & \multirow[t]{2}{*}{ Fallow } \\
\hline & & 1 & 2 & 3 & 4 & 5 & \\
\hline $\begin{array}{l}\text { Linear terms } \\
\text { Cross terms }\end{array}$ & 1.53 & 28.85 & 32.89 & 39.09 & 48.76 & 52.74 & 24.56 \\
\hline Wealth & -0.01 & 0.34 & 0.29 & 0.18 & 0.03 & -0.03 & 0.40 \\
\hline age-class 1 & & -1.93 & -3.29 & -1.72 & -0.25 & 0.05 & -4.46 \\
\hline age-class 2 & & & -1.56 & -1.65 & -0.44 & -0.25 & -3.87 \\
\hline age-class 3 & & & & -0.46 & -0.24 & -0.26 & -2.15 \\
\hline age-class 4 & & & & & -0.41 & -1.18 & -0.37 \\
\hline age-class 5 & & & & & & -0.82 & 0.05 \\
\hline Fallow & & & & & & & -2.71 \\
\hline
\end{tabular}

Table 4: Optimal harvesting and planting strategies in the recursive utility benchmark case

\begin{tabular}{c|cccccc}
\hline & \multicolumn{7}{|c}{ Initial wealth } \\
& 10 & 20 & 30 & 40 & 50 & 60 \\
\hline$a_{1}^{h *}$ & - & - & - & - & - & - \\
$a_{2}^{h *}$ & - & - & - & - & - & - \\
$a_{3}^{h *}$ & 0.2 & 0.2 & - & - & - & - \\
$a_{4}^{h *}$ & 0.2 & 0.2 & 0.2 & 0.2 & - & - \\
$a_{5}^{h *}$ & 0.2 & 0.2 & 0.2 & 0.2 & 0.2 & - \\
$a_{f}^{*}$ & - & - & - & - & - & - \\
$a_{p}^{*}$ & 0.6 & 0.6 & 0.4 & 0.4 & 0.2 & - \\
\hline
\end{tabular}


Table 5: Optimal consumption-saving decisions in the recursive utility benchmark case

\begin{tabular}{c|rrrrrr}
\hline & \multicolumn{7}{|c}{ Initial wealth } \\
& \multicolumn{1}{|c}{10} & \multicolumn{1}{c}{20} & \multicolumn{1}{c}{30} & \multicolumn{1}{c}{40} & \multicolumn{1}{c}{50} & \multicolumn{1}{c}{60} \\
\hline Available wealth from & 31.60 & 49.66 & 64.93 & 82.99 & 96.09 & 108.36 \\
- Forest profit (in \%) & 43 & 27 & 17 & 13 & 6 & 0 \\
- Saving (in \%) & 57 & 73 & 83 & 87 & 94 & 100 \\
Available wealth used for & 31.60 & 49.66 & 64.93 & 82.99 & 96.09 & 108.36 \\
- Consumption (in \%) & 29 & 28 & 30 & 34 & 41 & 48 \\
- Saving (in \%) & 71 & 72 & 70 & 66 & 59 & 52 \\
\hline
\end{tabular}

Table 6: Long-run equilibrium and forest-owner preferences

\begin{tabular}{ll|cccccccc}
\hline$\alpha$ & $\sigma$ & $W^{L R}$ & $c^{L R}$ & $A_{1, \cdots, 4}^{L R}$ & $a_{1, \cdots, 4}^{h^{L R}}$ & $A_{5}^{L R}$ & $a_{5}^{h^{L R}}$ & $A_{f}^{L R}$ & $a_{f}^{L R}$ \\
\hline 0.5 & $1 / 3$ & 59.168 & 1.921 & 0.136 & 0 & 0.458 & 0.136 & 0 & 0 \\
0.5 & $1 / 2$ & 55.003 & 1.762 & 0.104 & 0 & 0.585 & 0.104 & 0 & 0 \\
0.5 & $2 / 3$ & 53.910 & 1.722 & 0.098 & 0 & 0.610 & 0.098 & 0 & 0 \\
& & & & & & & & & \\
0.9 & $1 / 3$ & 58.350 & 1.885 & 0.125 & 0 & 0.500 & 0.125 & 0 & 0 \\
0.9 & $1 / 2$ & 55.014 & 1.762 & 0.104 & 0 & 0.584 & 0.104 & 0 & 0 \\
0.9 & $2 / 3$ & 53.989 & 1.727 & 0.099 & 0 & 0.603 & 0.099 & 0 & 0 \\
& & & & & & & & & \\
6 & $1 / 3$ & 58.451 & 1.891 & 0.128 & 0 & 0.489 & 0.128 & 0 & 0 \\
6 & $1 / 2$ & 55.174 & 1.772 & 0.108 & 0 & 0.567 & 0.108 & 0 & 0 \\
6 & $2 / 3$ & 54.299 & 1.743 & 0.106 & 0 & 0.575 & 0.106 & 0 & 0 \\
\hline
\end{tabular}

The superscript $L R$ denotes long-run equilibrium value. 
Figure 1: Value function for one ha of tree age-class plots, $J\left(A_{i}=1, A_{-i}=0, A_{f}=0, W\right)$, or one ha of fallow, $J\left(A_{i}=0, A_{-i}=0, A_{f}=1, W\right)$, as a function of wealth

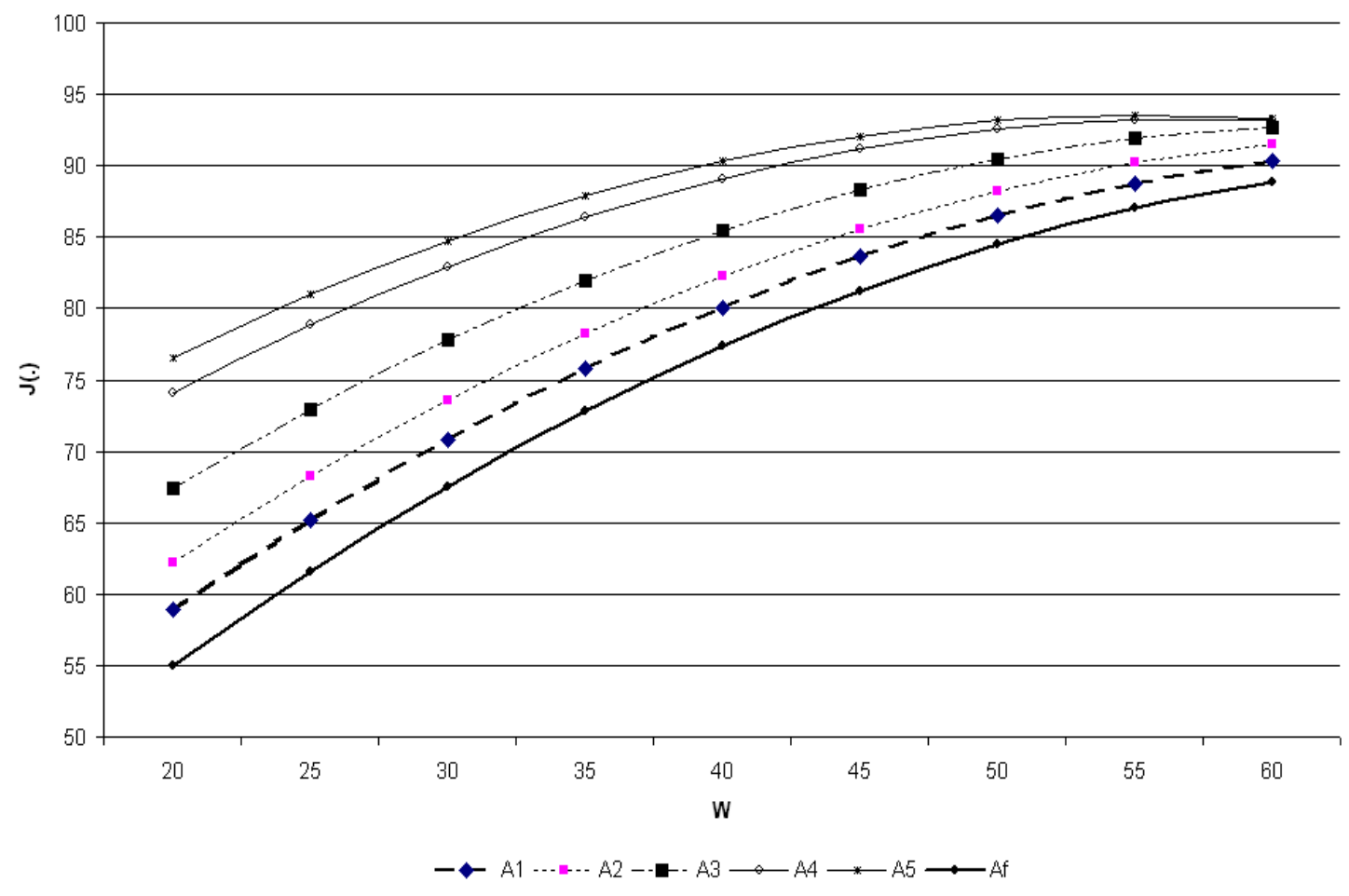


Figure 2: Wealth and consumption dynamic paths in the recursive utility benchmark case

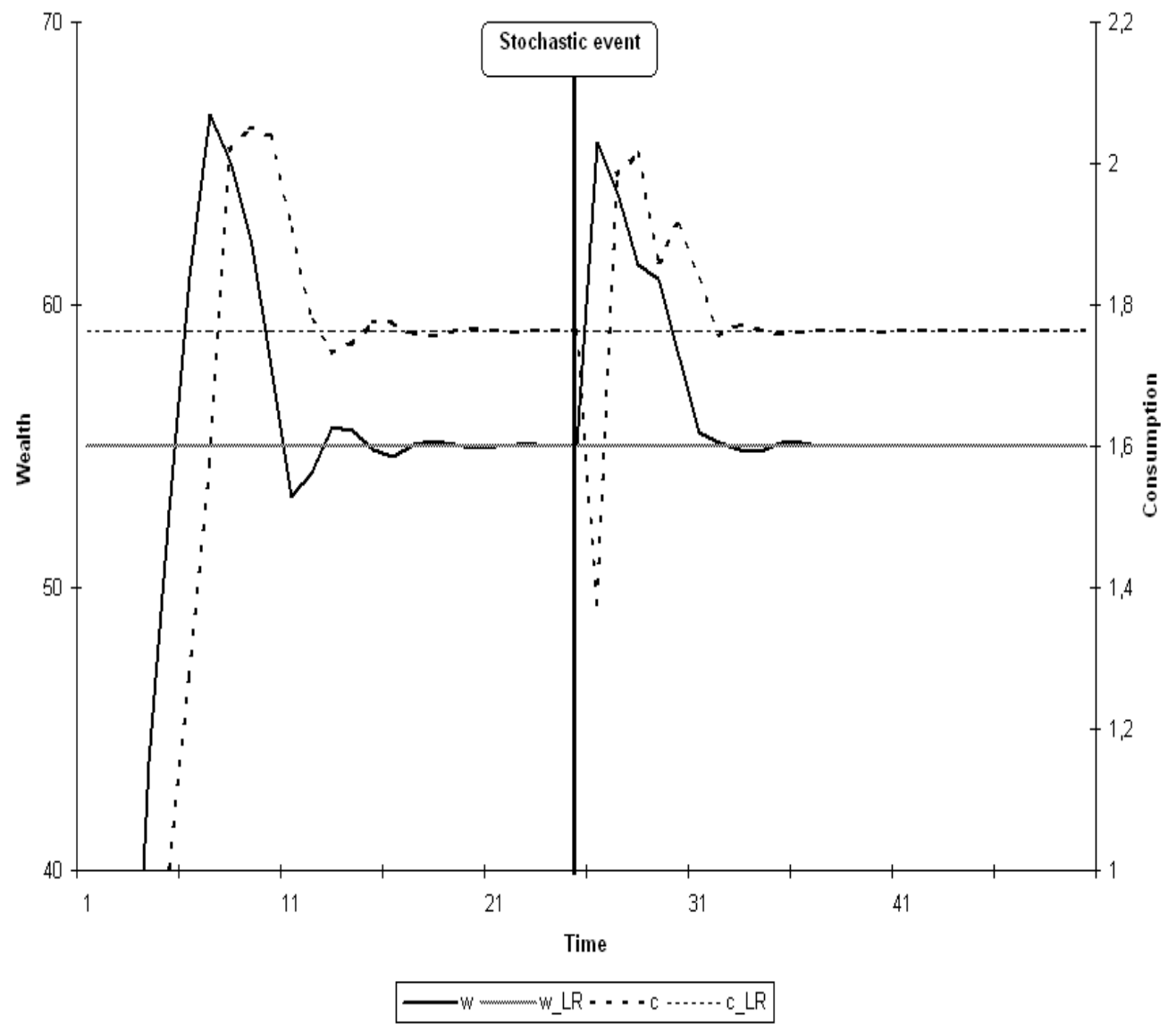

